\title{
Two Serial Case of Coronavirus Disease-19 Patients Coinfected with HIV: Comparison of Pre-anti-Retroviral (art) and on Art Patient
}

\author{
Ni Putu Ayu Widiasari ${ }^{1 *}$, Ni Luh Putu Eka Arisanti ${ }^{1}$, Ida Bagus Ngurah Rai ${ }^{1}$, Ida Sri Iswari ${ }^{2}$ \\ ${ }^{1}$ Department of Pulmonology, Faculty of Medicine, Udayana University, Sanglah General Hospital, Denpasar, Indonesia; \\ ${ }^{2}$ Department of Microbiology Clinic, Faculty of Medicine, Udayana University, Sanglah General Hospital, Denpasar, Indonesia
}

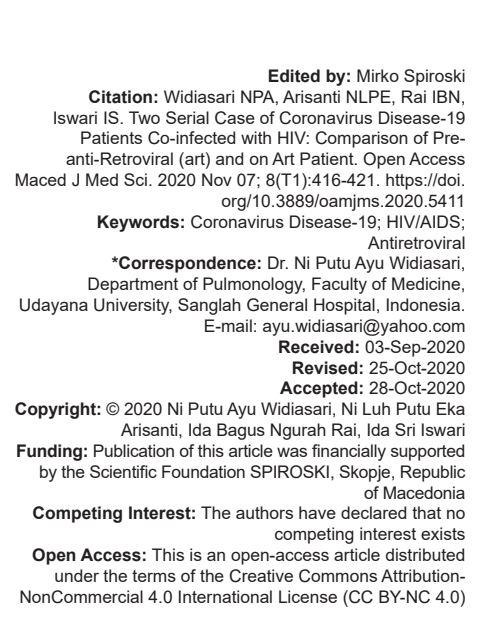

Abstract

BACKGROUND: Today, coronavirus disease (COVID)-19 has become a worldwide pandemic. People living with HIV are one of the special populations who are susceptible to COVID-19 infection and suspected of having a poor prognosis.

CASE REPORT: We reported two serial cases of COVID-19 with HIV coinfection. First case was a COVID-19 patient coinfected with HIV who had received anti-retroviral therapy (ARV) and had an absolute CD4 cell count of 781 cells/ uL. Patient was found with mild symptoms of COVID-19 and had normal laboratory results and chest X-ray. Patient was declared cured after 26 days of treatment in isolation room with complete clinical improvement since day 5 of isolation. Second case was a COVID-19 with HIV coinfection that had not yet received ARV therapy and had absolute CD4 cell count of 155 Cell/uL. Patient came with moderate clinical symptom of COVID-19 and experienced secondary bacterial and tuberculosis infection. Patient was declared cured of COVID-19 on the $8^{\text {th }}$ day of treatment with clinical improvement but still needed further treatment in a non-isolation room.

CONCLUSION: Clinical characteristics of COVID-19 in HIV and non-HIV patients are the same. A history of ARV therapy and CD4 count did not affect the length of isolation until a negative result on two reverse-transcriptionpolymerase chain reactions, but could affect prognosis and clinical severity due to the high risk of secondary infection in HIV-positive patients without ARV or HIVIAIDS who had a CD4 count $\leq 200$ cell/uL.

\section{Introduction}

Coronavirus (CoV) disease (COVID)19 infections that are caused by the severe acute respiratory syndrome (SARS)-COV-2 virus today become a worldwide pandemic [1]. Patients who had underlying diseases such as diabetes mellitus (DM), chronic kidney disease, hypertension, heart disease, and chronic lung disease based on epidemiological data more susceptible to get COVID-19 infection with more severe prognosis than the general population due to chronic systemic immunodeficiency and inflammatory conditions in patients [2]. Other immunodeficiency conditions such as people living with HIVIAIDS (PLWHA) are also thought to have a higher risk of becoming infected with COVID-19 with a worse prognosis.

Epidemiological facts regarding this matter are still inconclusive [3]. Articles about COVID-19 infection in HIVIAIDS patients still provide various results in terms of susceptibility to COVID-19 infection, clinical characteristics, symptom severity, and prognosis. In the COVID-19 with HIV coinfection case series written by Cooper et al. in 2020 said that viral load and CD4 count were factors that influenced the severity of symptoms, but not the individual's susceptibility to COVID-19 infection.
There was also another hypothesis which states that HIV is a protective factor for organ damage due to cytokine storms in COVID-19 patients with HIVIAIDS [4]. Research by Karmen-Tuohy et al. in 2020 with a number of subjects dominated by COVID-19 patients with controlled HIV infection showed no significant difference in mortality rates in HIV patients compared to controls (population without HIV) [5]. Another study article by Harter et al. in 2020 found significantly higher mortality, hospitalization, and critical infection rates in patients with COVID-19 coinfected with HIV than in the general population [6].

We reported two serial cases of COVID-19 with HIV coinfection. First case was a COVID-19 patient with HIV who was already undergoing anti-retroviral therapy (ARV) therapy and the second case was a COVID-19 patient with HIV who had not received ARV treatment.

\section{Case}

First case was a 67-year-old woman who came to the COVID-19 polyclinic with chief complaints sore throat and cough without sputum for last 3 days. 
Patient said that she had a history of close contact with a confirmed case of COVID-19. She is a PLWHA who regularly takes ARVs, rilpivirine $25 \mathrm{mg}$ every $24 \mathrm{~h}$, and tenofovir/emtricitabine $300 \mathrm{mg} / 200 \mathrm{mg}$ every $24 \mathrm{~h}$ and has hypertension as other comorbidity and has been controlled with Amlodipine $10 \mathrm{mg}$ every day. Physical examination was in normal limits. Twice reversetranscription-polymerase chain reaction (RT-PCR) nasopharyngeal swab diagnostic were performed and both tests were positive. Patient was hospitalized after being confirmed positive for COVID-19 through a nasopharyngeal RT-PCR swab examination. Both nasopharyngeal swab RT-PCR examined by kit that used Nucleocapsid 1, Nucleocapsid 2, and RNA-dependent RNA polymerase (RdRp) viral component as protein target. First RT-PCR swab obtained Cycle Treshold $\left(\mathrm{C}_{\mathrm{T}}\right)$ value for each target gene ware, respectively, 20.19; 20.84; and 27.82. Second RT-PCR swab obtained $C_{T}$ values for each target gene were, respectively, 18.55; 20.30; and 27.12. Complete blood count performed on the $1^{\text {st }}$ day of hospitalization was within normal limits, there was an increase in the Ferritin value of 480.30 and C-Reactive Protein of 5.87. Liver function tests showed a slight increase in aspartate aminotransferase (AST), which was 41.4 , while the alanine aminotransferase (ALT) value was within normal limits. Renal function tests were also found within normal limits. Patient's absolute CD4 count was 781 cells/uL. Patient also performed a chest X-ray at the time of admission to the hospital, with the result was no lung abnormality (Figure 1a).

During hospitalization, ARV therapy was continued. Patients received hydroxychloroquin at a dose of $400 \mathrm{mg}$ every $12 \mathrm{~h}$ orally on the $1^{\text {st }}$ day and continued with $200 \mathrm{mg}$ every $12 \mathrm{~h}$ until the $10^{\text {th }}$ day. Patients continue consume Amlodipine 10 mg every 24 $\mathrm{h}$ regularly and other symptomatic therapy. Evaluation of the RT-PCR swab examination was carried out every 5-7 days. The evaluation of the X-ray examination was carried out on the $16^{\text {th }}$ day of hospitalization with an normal lung configuration result (Figure $1 \mathrm{~b}$ ). The patient gets full recovery in the $5^{\text {th }}$ day of hospitalization and was declared cured after 26 days of treatment.

Second case was a woman, 43 years old, who came to the Emergency Unit with an acute complaint of fever since 6 days, cough with phlegm, and chest hard to breath since 1 day before admission accompanied

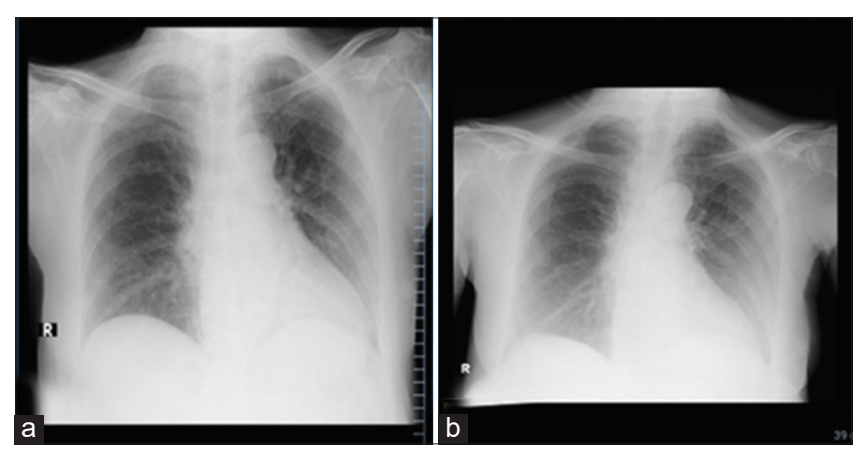

Figure 1: Chest $X$-ray of the first patient, (a) $1^{\text {st }}$ day of admission; (b) $6^{\text {th }}$ day after hospitalization by decreased appetite. Chronic symptom in the form of weight loss of $10 \mathrm{~kg}$ within 1 month was also found. Patient was currently undergoing intensive phase of antituberculosis treatment for lymphadenitis tuberculosis and had been diagnosed with HIV, but has not received ARV treatment. The history of contact with a confirmed COVID-19 person was unknown, but the patient lives in a local transmission area of COVID-19. On physical examination, there was an increase in body temperature $\left(38.6^{\circ} \mathrm{C}\right)$, increase in the respiratory rate of $22 \mathrm{times} / \mathrm{min}$, $\mathrm{SpO}_{2} 93 \%$ room air, and raunchy on lung auscultation in basal of the right lung. Laboratory examination was found normal leukocyte value with an increase in neutrophils percentage $(81 \%)$, Iymphopenia $\left(0.4210^{3} /\right.$ $\mu \mathrm{L})$, moderate anemia $(7.58 \mathrm{~g} / \mathrm{dl})$, and thrombocytopenia $\left(92.9510^{3} / \mu \mathrm{L}\right)$. There was also an increase in the AST and ALT values, respectively, 386.8 and 52.60. Patient's absolute CD4 count at admission was 155 cells / uL. A chest $X$-ray on the $1^{\text {st }}$ day of hospitalization showed a reticular pattern in both lung fields (Figure 2a). Patient was diagnosed with a suspected COVID-19 accompanied by community pneumonia and was treated in an isolation room. Furthermore, a diagnostic RT-PCR nasopharyngeal swab examination was carried out. First RT-PCR was positive for COVID-19 and second RT-PCR was found negative for COVID-19. RT-PCR examination used kit with the non-sturctural protein 1 (NSP-1) gene as a positive control. First RT-PCR swab obtained CT values for positive control and internal control were 37.98 and 33.56 , respectively. The patient was diagnosed with confirmed COVID-19 and treatment was continued in an isolation room. RT-PCR swab evaluations were carried out every 5-7 days and chest $\mathrm{X}$-ray evaluations were carried out when the patient was declared cured of COVID-19.

During hospitalization, patients received empiric antibiotic therapy in the form of Cefoperasonsulbactam $1 \mathrm{~g}$ every $12 \mathrm{~h}$ intravenously and Levofloxacin 750 mg every $24 \mathrm{~h}$ intravenously for 7 days, symptomatic therapy, and continued anti-tuberculosis treatment. Patient did not receive antiviral treatment. Patient was declared cured of COVID-19 on the $8^{\text {th }}$ day of treatment after two negative RT-PCR results. Patient left the isolation room with partial clinical improvement and further treatment was carried out in the non-isolation

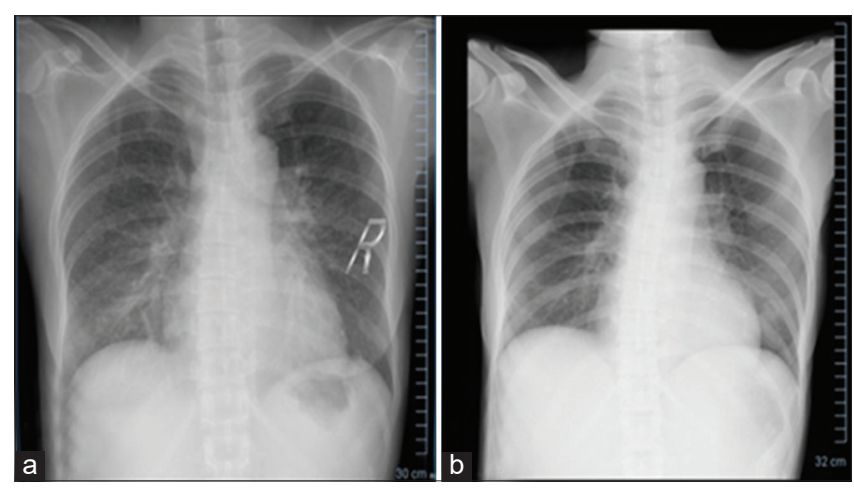

Figure 2: Chest $X$-ray of second patient, (a) $1^{\text {st }}$ day of admission; (b) the last day of hospitalization 
room. The evaluation of the chest X-ray when the patient was declared cured showed a reduction of lung infiltrate (Figure 2b).

\section{Discussion}

Today, there have been various articles that discuss about characteristics of COVID-19 infection in HIV patients [4]. Immunodeficiency in HIV is thought to be a factor that increases the risk of COVID-19 infection. CD4 count and viral load are also thought to be factors that influence the poor prognosis in patients, but several articles have shown various results [7]. In this article, two case series of COVID-19 with HIV coinfection were reported comparing HIV cases with ARVs and HIV without ARVs.

In a study conducted by Huang et al. in 2019 regarding the clinical characteristics of COVID19 patients in Wuhan, the median age of COVID-19 patients was found to be 49 years. That study used 41 subjects with $32 \%$ of them having underlying diseases such as DM, hypertension, and cardiovascular disease, but none of the subjects had HIV infection. It was found median time of hospital stay was 7 days after symptom onset and experienced dyspnea 8 days after symptom onset. It also mentioned some of the major symptoms experienced by the patients, including fever ( $98 \%$ subjects), cough ( $76 \%$ subjects), and myalgia or fatigue in $44 \%$ of subjects [2]. Another study conducted by Harter et al. in 2020 regarding the characteristics of COVID-19 cases with HIV coinfection obtained similar median age with the previous studies; it was 48 years with range of 26-82 years. In our study, all subjects had received ARV therapy and had a median $\mathrm{CD}^{+}$ count $670 / \mathrm{mm}^{3}$. It also mentioned some of the major symptoms experienced by the patient; they were cough (78\%), fever $(69 \%)$, atralgia or myalgia $(22 \%)$, and sore throat (22\%) [6]. A case report by Patel et al. in 2020 regarding a COVID-19 patient with HIV coinfection aged 37 years who had an absolute CD4 cell count 34 cells/uL had experiencing symptoms such as fever, dry cough, and chest pain since 1 month before being admitted to the hospital. Physical examination found that high body temperature of $38.8^{\circ} \mathrm{C}$, oxygen saturation $\left(\mathrm{SpO}_{2}\right)$ of $85-90 \%$ on ambient air, with high respiratory rate (40 beats/min), and pulse rate were 119 beats/min [8].

Demographic and clinical characteristics of two patients in this case report were similar to those of the patients in other case reports. COVID-19 patients with HIV and without HIV have similar demographic and clinical characteristics. Patients who have received ARV and have CD4 + count $\geq 200$ cells /uL showed mild COVID-19 clinical symptom with cough without phlegm and sore throat. Patients who have not received ARVs with CD4 + counts <200/uL showed moderate clinical symptom of COVID-19 with cough, fever, accompanied by hard to breath sensation and increase in respiratory rate. Based on the case report by Patel et al. in 2020, clinical severity of the second patient could be affected by the possibility of secondary infection. Viremia was also cannot rule out as a caused of more severe clinical symptom in the second patient [8].

First patient had normal laboratory results and chest X-rays. Second patient's laboratory examination showed an increase in neutrophils percentage, lymphopenia, and thrombocytopenia accompanied by a reticular pattern on chest X-rays. Second patient also had chronic symptoms such as weight loss associated with lymphadenitis tuberculosis beside signs of acute infection caused by bacteria or other opportunistic infections.

In a study conducted by Huang et al. in 2019 on the COVID-19 population without coinfection, only four patients $(10 \%)$ had secondary infections and required intensive care. Laboratory results showed normal leukocyte values (in $45 \%$ of patients), with an average absolute neutrophil count was $5 \times 10^{3} / \mathrm{L}$, leukopenia occurred in $63 \%$ of patients, normal platelet values were found in $95 \%$ of patients, and dominantly liver and kidney function were found. Within normal limits with a mean procalcitonin value was 0.1 . A case series in Barcelona, Spain regarding COVID-19 with HIV coinfection by Blanco et al. in 2020 comparing four patients who were taking ARVs routinely and had an absolute CD4 + count> 200/uL and one patient who had not taken ARVs and had a CD4 + count <200/uL. Two patients who had received ARV therapy had mild clinical symptom without laboratory and chest X-ray abnormalities, two patients who received ARV had moderate symptoms, and one patient who had no ARV and had a CD4 ${ }^{+} 13$ Cell/uL count had severe COVID19 symptoms with secondary bacterial infection signs such as increase in leukocyte to 14,670 cells per $10^{3} / \mathrm{L}$. Lymphopenia occurred in two cases with ARV and one case withoutARV with the lowest lymphocyte count value were 900 cells per $10^{3} / \mathrm{L}$ [9]. Case reports by Wang et al. in 2020 have different characteristics. They reported COVID-19 patients with HIV coinfection and a CD4 ${ }^{+} 34$ Cell/uL count had a severe clinical presentation but no leukocytosis or signs of secondary infection, especially bacterial infection [10]. Other secondary infections that can occur in HIV patients are Pneumocystis carinii (Pneumocystis pneumonia [PCP]), tuberculosis, Hepatitis B, Hepatitis C, Cryptococcal Meningitis, and Toxoplasmosis [11]. It can be considered to conduct a clinical evaluation of the infection if you get a COVID-19 patient with HIV coinfection to improve the prognostic outcome of the patient, especially HIVIAIDS patients who have a CD4 + count $<200$ Cells/uL.

In this case report, first case had normal laboratory and chest X-ray result, while second case showed normal leukocyte values accompanied by increased in neutrophil, lymphopenia, moderate anemia, and thrombocytopenia. A normal leukocyte value in HIV 
patients does not absolutely rule out the possibility of secondary infection, especially bacterial infection. Based on a study conducted by Huson et al. in 2016 in patients with bacteremia, it was found that increasing of leukocyte average in HIV patients was lower than nonHIV patients. That study was conducted on patients with a mean $\mathrm{CD}^{+}$count 150 cells/uL [12]. In case series reported by Blanco et al. in 2020, HIV patients who had a CD4 + count $>200$ cell/uL and were already taking ARVs routinely showed a higher increase in leukocytes than HIV patients with CD4 $4^{+}$counts $<200$ cells/uL and had not received ARVs [9]. Lymphopenia and thrombocytopenia were accompanied by a reticular pattern in chest X-ray consistent with viral infection sign. Mild anemia can be caused by chronic inflammation due to tuberculosis and HIV. Nutritional intake from food can also affect the occurrence of anemia in patients. Various articles have reported no significant association between HIV conditions and the risk of SARS-COV-2 infection; however, severe lymphopenia in HIVIAIDS patients with COVID-19 can affect the severity of symptoms. Based on research conducted by Qin et al., it was found that the number of B cells, T cells, and NK cells significantly decreased in COVID-19 patients. If coupled with HIV/ AIDS can cause severe lymphopenia, thereby increasing the risk of severe pneumonia and secondary infection in HIV patients which affect the severity of symptoms and poor prognosis [13].

The SARS-COV2 viral nucleic acid RT-PCR test from nasopharyngeal swab is currently the standard method to diagnosed COVID-19 [14]. First patient had twice positive diagnostic swab PCR results, while the second patient had only one positive PCR diagnosis. SARS-COV-2 RT-PCR examination result can be influenced by various factors, such as the type of specimen, specimen collection time, number of viruses, and examination tool or kit [15].

Specimen type can determine the rate of positivity for RT-PCR examinations in COVID-19. There are several types of specimens that can be used; they are Bronchoalveolar lavage (BAL), Fibro bronchocope biopsy, sputum, nasopharyngeal swab, oropharyngeal swab, feces, and urine. Nasopharyngeal swab and oropharyngeal swab are two types of specimens that are commonly used as samples for COVID-19 testing in the world, especially in Indonesia. This is due to easy sampling process with a high positive rate [15]. Based on the article written by Wang et al. in 2020 , the nasopharyngeal and oropharyngeal swab positivity rates were $63 \%$ and $32 \%$, respectively, where nasopharyngeal swab was superior to oropharyngeal. Specimens derived from BAL and sputum are two types of specimens that have the highest rate of positivity compared to other specimen types with the percentage of positivity, respectively, $93 \%$ and $72 \%$ [15]. Systematic review article with meta-analysis method also shows the same thing, specimens derived from nasopharyngeal swabs have a lower sensitivity than sputum, where sputum has a sensitivity of $97.2 \%$ with a $95 \%$ confidence interval of $90.3-99.7 \%$ [16]. In this case, a negative result on one of the diagnostic swab examinations of the second patient could be due to the rate of positivity of the specimen used.

Specimen collection time and number of viruses can also affect the SARS-COV-2 RT-PCR results. Timing of specimen collection is related to the presence of the SARS-COV2 virus in the examination specimen [16]. Research conducted by Wang et al. in 2020 regarding differences in shedding duration for sputum and nasopharyngeal swabs specimens found a correlation between viral shedding time and the positivity of each specimen. In this study, it was found that median duration of viral shedding from sputum was 34 days, while viral shedding from nasopharyngeal swab specimens was 19 days. Nine patients found positive sputum specimens after negative nasopharyngeal swab examination. Chronic lung disease and systemic steroid use was also found to be associated with viral detection in sputum specimens; however, HIVIAIDS was not mentioned as a factor affecting the location of viral shedding [17]. Specimen collection time is also related to the amount of virus in the nasopharyngeal specimen. In a study by Lirong et al. in 2020, the highest number of viruses in nasopharyngeal swab specimens was found on days 3-6 after the onset of symptoms and began to decline on the $7^{\text {th }}$ day after symptoms [18]. The incubation period must also be taken into account as a factor for bias in the results of nasopharyngeal swabs [19]. Hence, a negative result on nasopharyngeal RT-PCR swab can also be caused by the location of the viral shedding which is not suitable for the specimen and the time of specimen collection.

There are various kits that are used in Indonesia with different gene targets or primers [20]. Two patients on the diagnostic swab used a different kit, where first patient used a kit that detected N1, N2, and RdRp as gene target while the second patient used a kit targeting the NSP-1 gene as gene target. Target gene largely determines the sensitivity and specificity of an assay. Multitarget RT-PCR can improve the accuracy of the RT-PCR results, because negative results can be found in one of the target genes if there is a mutation in that section [21]. Second patient had one negative RT-PCR diagnostic nasopharyngeal swab. This can be affected by the RT-PCR kit used. Based on research conducted by Chan et al. in 2020 regarding the detection accuracy of the NSP-1 gene for COVID-19 diagnostics in 101 clinical specimens, the test sensitivity and specificity were $93.1 \%$ (95\% confidence interval 86.2-97.2\%) and $100 \%$ (95\% confidence interval 92.9-100\%), so there is still a possibility of false negatives in approximately $6.9 \%$ of the specimens [22]. The $\mathrm{C}_{\mathrm{T}}$ value of the second patient was higher than first patient, but could not be compared because of differences in target genes in the two RT-PCRs kit. These results can be used to illustrate the relationship between baseline $C_{T}$ values and the length of time to achieve negative RT-PCR nasopharyngeal swab evaluation results. 
Recommendation therapy for COVID-19 patients with HIV coinfection is similar to COVID-19 without HIV coinfection [14]. The high risk of secondary infection in HIVIAIDS patient's makes the optimization of secondary infection therapy was very important [4]. Giving systemic steroids to COVID-19 patients with HIV coinfection are still recommended, especially in patients with severe clinical COVID-19 or with secondary infection in the form of severe PCP, although systemic steroid administration in a study conducted by Huang et al. in 2020 and Wang et al. in 2020 said could be slowering viral clearance and prolong viral shedding period [2], [17]. The recommendations issued by British and American health institutions for people with HIV during the pandemic are to ensure that they have a supply of ARVs and that they are vaccinated against Influenza and Pneumococci regularly. Until now, there have been no specific reports regarding the relationship between the types of ARVs used and the severity of COVID-19 symptoms in patients with HIV, but there is a case series that show clinical differences in patients with different history of ARVs [9]. A case series report by Blanco et al. in 2020 showed two patients taking the combination of the ARVs tenofovir alafenamide, emtricitabine, and darunavir-boosted Cobicistat had mild symptoms of COVID-19 and two patients taking the combination of the ARV abacavir, lamivudine, and dolutegravir had a moderate to severe COVID-19 presentation and require intensive care [9]. Combination of Lopinavir and Ritonavir in in vitro studies can shorten viral shedding period, but its effectiveness in clinical studies of COVID-19 has not been shown to significantly increase patient outcomes compared to standard therapy [23].

The outcome of COVID-19 patients can be assessed based on the length of time to achieve negative result in nasopharyngeal RT-PCR swab and morbidity and mortality risk. First patient had a negative RT-PCR nasopharyngeal swab on the $26^{\text {th }}$ day of treatment and the second patient had a negative result on the $8^{\text {th }}$ day of treatment. A case report by Wang et al. in 2020 regarding a COVID-19 patient with HIV coinfection who had a CD4 + count $<200$ Cells/ $\mathrm{UL}$ reported something similar to the second case, it was only getting positive results on the first RT-PCR and negative on 3 RT-PCR nasopharyngeal swab evaluation. It is due to the baseline value of each $C_{T}$, but cannot be compared because of using a kit with different target genes. Another possibility is second patient's viral shedding on the day of evaluation was found in the sputum, so it was not detected in the nasopharyngeal swab specimen. Two cases reported by Menghua et al. in 2020 showed long cases of COVID 19 and it took 28 days to get a negative RT-PCR swab, but, in this case, RT-PCR was carried out on a sputum specimen. This can be due to prolonged viral shedding in patients associated with damage to cellular function of CD4 + cells even though the CD4 + cell count is within normal limits [24]. The outcome of mortality risk in several articles is still inconclusive. Systematic review article on COVID-19 in HIV patients by Cooper et al. 2020 said that patients with HIV with an undetectable viral load and an adequate CD4 cell count had no worse outcome than the general population. Uncontrolled HIV infection and AIDS are one of the factors in the poor prognosis of patients with COVID-19. This is associated with the occurrence of bacterial superinfection in patients [4]. Another study by Karmen-Tuohy et al. in 2020 with the number of subjects dominated by COVID-19 patients with controlled HIV showed no significant difference in mortality rates between HIV patients and control (population without HIV) [5]. Another study article by Harter et al. in 2020 found significant higher mortality, hospitalization, and critical infection rates in patients with COVID-19 with HIV than general population. In those studies, mortality rate in COVID-19 patients with HIV was $9 \%$ [6].

\section{Conclusion}

The clinical and demographic characteristics of COVID-19 in HIV and non-HIV patients are the same. A history of antiretroviral therapy and CD4 count did not affect the outcome of the length of care until a negative result on two RT-PCRs, but could affect prognosis and clinical severity due to the high risk of secondary infection in HIV-free or HIVIAIDS patients who had a CD4 count $\leq 200$ Cell/uL.

\section{Future Research}

Further research is needed regarding: (1) The accuracy of RT-PCR swab examinations in various specimens, especially in HIVIAIDS patients who have a CD4 + count <200/uL; (2) the effect of various combination ARV therapy in COVID-19 patients with HIV coinfection on the severity of clinical symptoms and the prognosis of COVID-19 patients; (3) antiviral and supportive therapy options in COVID-19 patients with HIV coinfection; (4) patient prognosis COVID-19 with HIV coinfection and factors affecting the prognosis.

\section{References}

1. World Health Organization. WHO Coronavirus Disease (COVID-19) Dashboard. Disitasi Dari. Available from: https:// www.covid19. who.int/?gclid=Cj0KCQjw-O35BRDVARIsAJ U5mQV2qLRIhmHMPUdZtpA5CIMAjIvSs8D5ONSDyMnqVAoZ4xxrVbOEjlaAm5gEALw_wcB. [Last accessed on 2020 
Aug 18].

2. Huang C, Wang $\mathrm{Y}$, Li X, Zhao J, Hu Y, Zhang L, et al. Clinical features of patients infected with 2019 novel coronavirus in Wuhan, China. Lancet. 2020;395(10223):497-506. https://doi. org/10.1016/s0140-6736(20)30183-5

PMid:31986264

3. Vishnevetsky A, Levy M. Rethinking high-risk groups in COVID-19. Mult Scler Relat Disord. 2020;42:102139. https:// doi.org/10.1016/j.msard.2020.102139

PMid:32388461

4. Cooper TJ, Woodward BL, Alom S, Harky A. Coronavirus disease 2019 (COVID-19) outcomes in HIVIAIDS patients: A systematic review. HIV Med. 2020;21(9):567-77. https://doi. org/10.1111/hiv.12911

PMid:32671970

5. Karmen-Tuohy S, Carlucci PM, Zacharioudakis IM, Zervou FN, Rebick G, Klein E, et al. Outcomes among HIV-Positive Patients Hospitalized with COVID-19. New York: MedRxiv; 2020. https:// doi.org/10.1101/2020.05.07.20094797

6. Härter G, Spinner CD, Roider J, Bickel M, Krznaric I, Grunwald S, et al. COVID-19 in people living with human immunodeficiency virus: A case series of 33 patients. Infection. 2020;48(5):681-6. https://doi.org/10.1007/s15010-020-01438-z

PMid:32394344

7. Zhao J, Liao X, Wang H, Wei L, Xing M, Liu L, et al. Early virus clearance and delayed antibody response in a case of COVID19 with a history of co-infection with HIV-1 and HCV. Clin Infect Dis. 2020:1-3:ciaa408.

PMid:32270178

8. Patel RH, Pella PM. COVID-19 in a patient with HIV infection. J Med Virol. 2020;92:2356-2357.

PMid:32441773

9. Blanco JL, Ambrosioni J, Garcia F, Martínez E, Soriano A, Malolas J, et al. COVID-19 in patients with HIV: Clinical case series. Lancet. 2020;7(5):e314-6. https://doi.org/10.1016/ s2352-3018(20)30111-9 PMid:32304642

10. Wang $M$, Luo L, Bu H, Xia $\mathrm{H}$. One case of coronavirus disease 2019 (COVID-19) in a patient co-infected by HIV with a low CD4 + T-cell count. Int J Infect Dis. 2020;96(2020):148-50. https:// doi.org/10.1016/j.ijid.2020.04.060 PMid:32335339

11. Vaillant AA, Naik R. HIV-1 Associated Opportunistic Infections. Treasure Island, FL: StatPearls Publishing; 2020.

12. Huson MA, Stolp SM, Van Der Poll T, Grobusch MP. Communityacquired bacterial bloodstream infections in HIV-infected patients: A systematic review. Clin Infect Dis. 2020;58(1):79-92. https://doi.org/10.1093/cid/cit596

PMid:24046307

13. Qin C, Zhou L, Hu Z, Zhang S, Yang S, Tao Y, et al. Dysregulation of immune response in patients with coronavirus 2019 (COVID-19) in Wuhan, China. Clin Infect Dis. 2020;71(15):7628. https://doi.org/10.1093/cid/ciaa248

PMid:32161940
14. Kementerian Kesehatan Republik Indonesia. Pedoman Pencegahan dan Pengendalian Coronavirus Disease (COVID-19). Jakarta: Kementerian Kesehatan Republik Indonesia; 2020. https://doi.org/10.7454/jki.v19i3.469

15. Wang W, Xu Y, Gao R. Detection of SARS-CoV-2 in Different Types of Clinical Specimens. JAMA. 2020;323(18):1843-4. PMid:32159775

16. Böger $B$, Fachi MM, Vilhena RO, Cobre AF, Tonin FS, Pontarolo R. Systematic review with meta-analysis of the accuracy of diagnostic tests for COVID-19. Am J Infect Control. 2020;1(2020):S0196-6553(20)30693-3. https://doi. org/10.1016/j.ajic.2020.07.011

PMid:32659413

17. Wang K, Zhang X, Sun J, Ye J, Wang F, Hua J, et al. Differences of severe acute respiratory syndrome coronavirus 2 shedding duration in sputum and nasopharyngeal swab specimens among adult inpatients with coronavirus disease 2019. Chest. 2020;S0012-3692(20):31718-9. https://doi.org/10.1016/j. chest.2020.06.015 PMid:32569635

18. Zou L, Ruan F, Huang M, Liang L, Huang H, Hong Z, et al. SARS-CoV-2 viral load in upper respiratory specimens of infected patients. N Eng J Med. 2020;382(12):1177-9. https:// doi.org/10.1056/nejmc2001737

PMid:32074444

19. Lauer SA, Grantz KH, Bi Q, Jones FK. The incubation period of coronavirus disease 2019 (COVID-19) from publicly reported confirmed cases: Estimation and application. Ann Intern Med. 2020;172(9):577-82. https://doi.org/10.7326/m20-0504 PMid:32150748

20. Kementerian Kesehatan Republik Indonesia. Strateg Percepatan Diagnosis COVID-19 di Indonesia Direktur P2PML, Ditjen P2P. Jakarta: Kementerian Kesehatan Republik Indonesia;2020. https://doi.org/10.7454/jki.v19i3.469

21. Van Kasteren $P B$, Van Der Veer $B$, Van Den Brink $S$, Wijsman L, De Jonge J, Van Den Brandt $A$, et al. Comparison of seven commercial RT-PCR diagnostic kits for COVID-19. J Clin Virol. 2020;128(2020):104412. https://doi. org/10.1101/2020.04.22.056747

22. Chan WM, Ip JD, Chu AW, Yip CC, Lo LS, Chan KH, et al. Identification of nsp1 gene as the target of SARS-CoV-2 realtime RT-PCR using nanopore whole-genome sequencing. J Med Virol. 2020;92:2725-2743. https://doi.org/10.1002/jmv.26140 PMid:32501535

23. Yan D, Liu XY, Zhu YN, Huang L, Dan BT, Zhang GJ, et al. Factors associated with prolonged viral shedding and impact of lopinavir/ ritonavir treatment in hospitalised non-critically ill patients with SARS-CoV-2 infection. Eur Respir J. 2020;56(1):2000799. https://doi.org/10.1183/13993003.00799-2020 PMid:32430428

24. Menghua W, Xin Z, Jianwei L, Qinwei Y. Case report: One case of coronavirus disease 2019 (COVID-19) in a patient co-infected by HIV with a normal CD4+ T cell count. AIDS Res Ther. 2020;17:46. https://doi.org/10.1186/s12981-020-00301-3 PMid:32703286 